\section{Congenital Pseudoarthrosis of The Clavicle; A Rare Case}

CASE REPORT

\section{Abstract}

Congenital pseudoarthrosis of clavicle (CPC) is a rare disease. It usually presents as a swelling in the clavicular region at birth or soon after birth. CPC first reported by FitzWilliams in 1910. In this anomaly, condition is caused by extrinsic pressure exerted on the budding clavicle by the adjacent pulsatile subclavian artery. The best time for surgery and the best method of surgery is controversial. Surgical indication for many authors is the presence of symptoms, functional impairment or cosmetic deformities. We present a 10 years old girl with a focal painless swelling in the midpoint of the right clavicle that finally diagnosed Congenital pseudoarthrosis of clavicle. We operated the patient and removed dense fibrotic tissue, clavicle ends freshed and local bone graft was fixed with plate. According to our results, we recommend $\mathrm{ORIF}^{1}$ of clavicle with local bone graft because of complete united bone without iliac crest bone graft and its morbidity. Finally we suggest usage of locking plate because of osteoporotic nature of this condition.

\section{Keywords}

Pseudoarthrosis, Congenital, clavicle
Salman Ghaffari ${ }^{1}$, Masoud Shayesteh Azar2, Mohammad Hossein Karimi Nasab', Seyed Mohamad Mehdi Daneshpoor ${ }^{3}$.

1 Assistant professor of Orthopaedic Surgery, Mazandaran University of Medical Science, Imam Khomeini Hospital, Sari, Iran.

2 Associate professor of Orthopaedic Surgery, Mazandaran University of Medical Science, Imam Khomeini Hospital, Sari, Iran.

3 Orthopaedic resident of Mazandaran University of Medical Science, Imam Khomeini Hospital, Sari, Iran.

\section{Contact information:}

Seyed Mohamad Mehdi Daneshpoor.

ĐMDaneshpour@mazums.ac.ir

\title{
Introduction
}

Congenital pseudoarthrosis of clavicle (CPC) is a rare condition that usually presents as a swelling in the clavicular region at birth or soon after birth, mostly found in girls and in the mid-right clavicle [1, 2]. Possible genetic transmission of this disease has been suggested by a Autosomal dominant trait [3]. Radiological features of the current condi-

1. ORIF: Open Reduction and Internal Fixation. 
tion include involvement of the middle part of the clavicle with a definitive separation into two parts [4]. Treatment is controversial and included surgical or non operative treatment. Surgical indication for many authors is the presence of symptoms, functional impairment or cosmetic deformities [5]. By this subject we present a 10 years old girl with this disorder.

\section{Case report}

A 10 years old girl referred to our clinic in Imam Khomeini hospital, Sari with a focal non-tender and mass-like swelling in the midpoint of the right clavicle (figure 1). Her parents found this condition when she was 1 year old but the surgeon suggested conservative treatment, now because of mass enlargement and concerning about cosmesis especially she referred to our outpatient clinic. She had no pain, no functional deficit and no vascular or neural problem at the upper extremity. Also she didn't compliant from weakness and she was fully active. On examination, skin was intact and a mass-like swelling was obvious. There was no erythema,ecchymosis and also structural deformity. Her parents denied history of trauma at the past or previous fracture and also familial history of similar disorders. On the radiologic assessment she had clavicle non union (figure 2). We diagnosed congenital pseudoarthrosis of the right clavicle based on the family explanation, radiography and physical examination. After explanation of the diagnosis and its natural history to patient and her parents, they decided to operate because of cosmesis. We operated the patient in the beach chair position. On surgery there was dense fibrotic tissue before two ends of clavicle (figure 3 ). This fibrotic tissue was removed to and after clavicle ends freshed and bone removal to match both ends the bone was fixed with plate. We had only reconstruction plate at the time of operation but because of osteoporotic nature of clavicle we had
Figure 1: Clinical appearance of our patient shows swelling in the midpoint of the right clavicle.

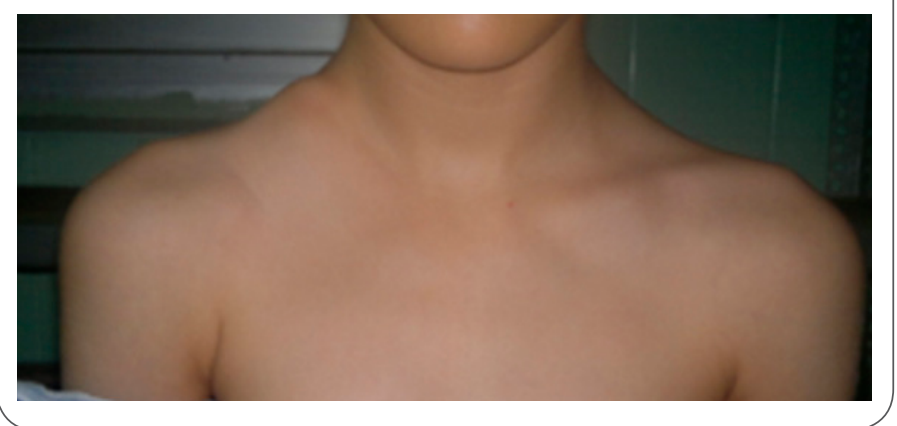

Figure 2: This radiography shows the pseudoarthrosis of clavicle.

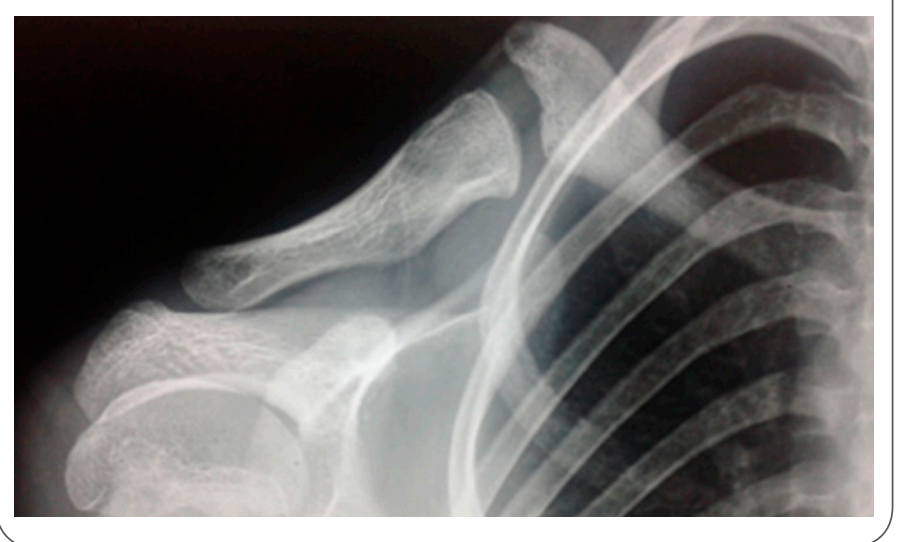

Figure 3: At the operation time fibrotic tissue was seen in the midpoint of the clavicle.

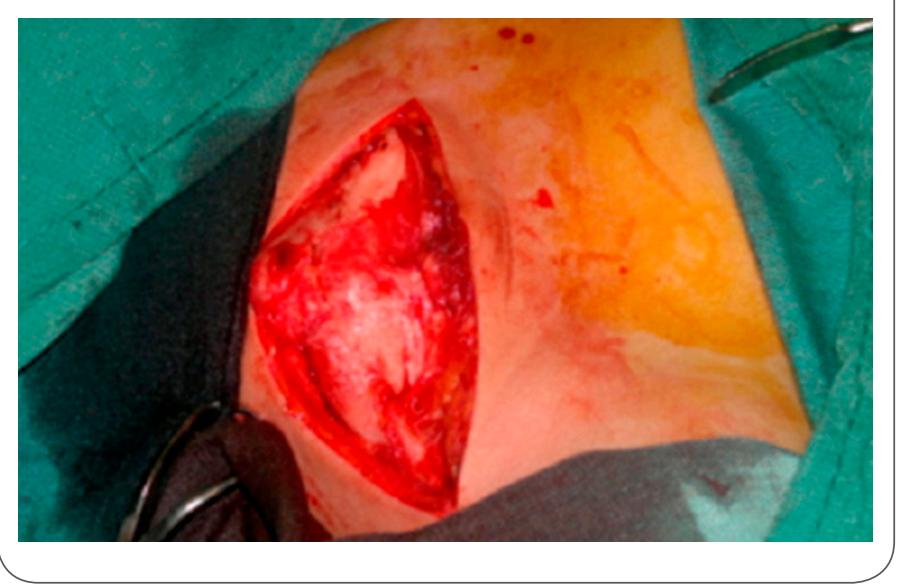


to fix the bone by dual plate (figure 4). Local bone was used for bone grafting. At about 3 months post operation the clavicle completely united. The patient was pain free with full shoulder ROM ${ }^{2}$ and normal function. She was pleased with new appearance. After 12 months follow up the patient came back for plate removal. In this second operation both plates were removed. The bone was completely united either in the radiograpghy and at operation (figures 5,6 ). On the X-ray that was taken after this surgery, right clavicle was only 5 $\mathrm{mm}$ shorter than left clavicle. (figure 7). Last photograpghy shows appearance of the patient after plate removal (figure 8).

Figure 4: Post operation radiograph shows dualplate for fixation.

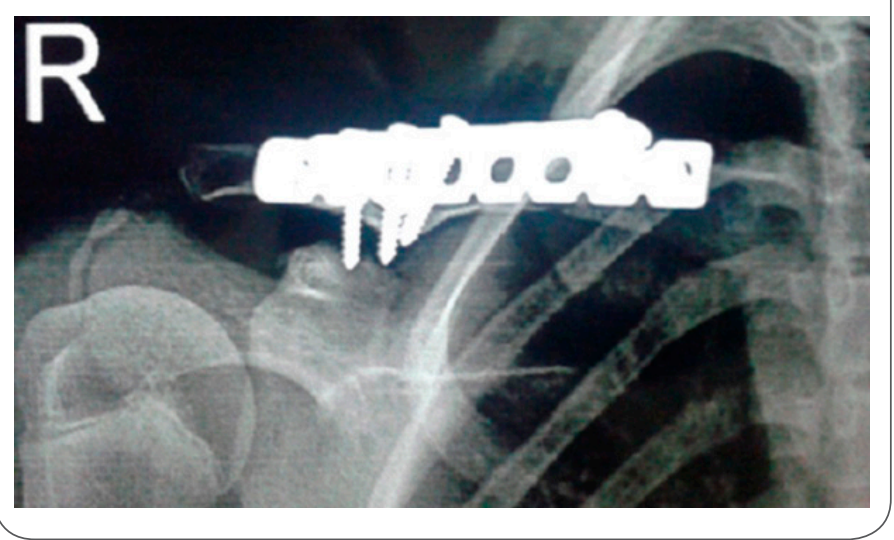

Figure 5: At the second operation the clavicle was united completely.

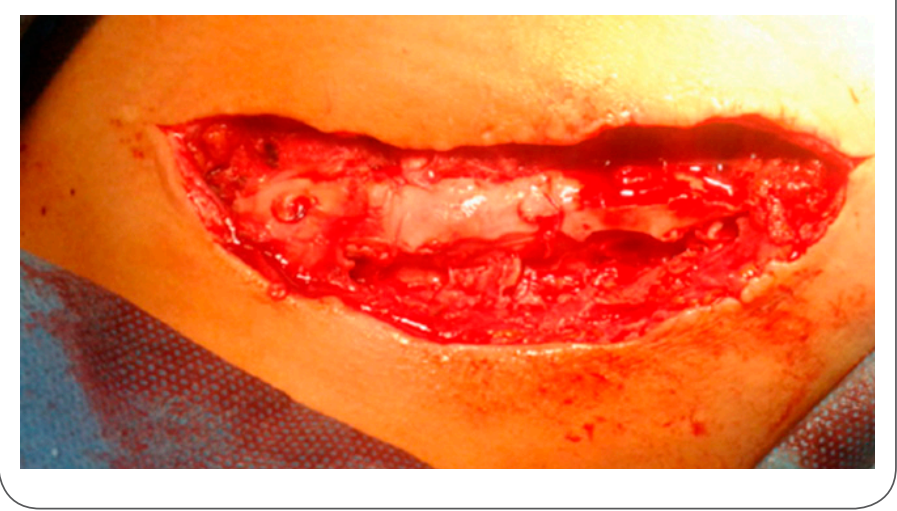

Figure 6: Post operation radiograph shows the clavicle was united completely.

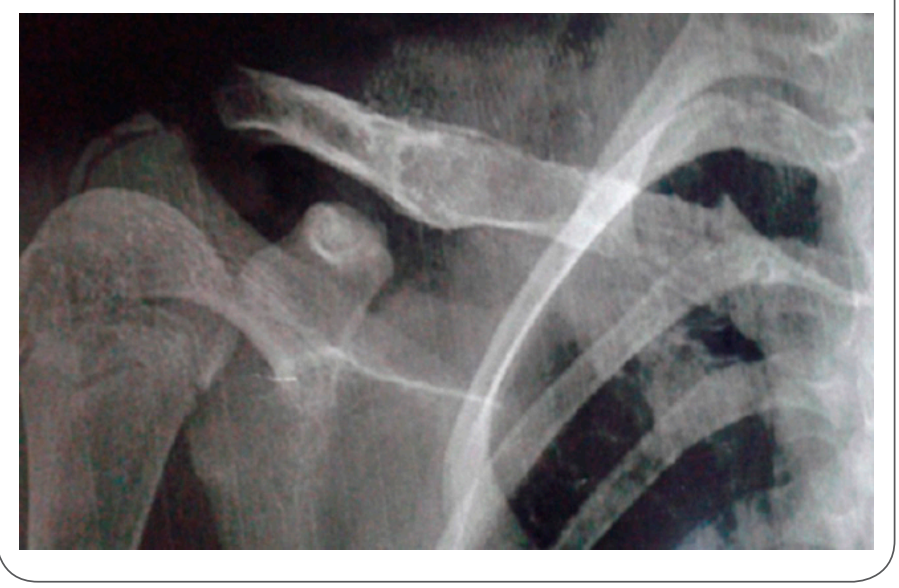

Figure 7: CXR shows right clavicle was only $5 \mathrm{~mm}$ shorter than left clavicle.

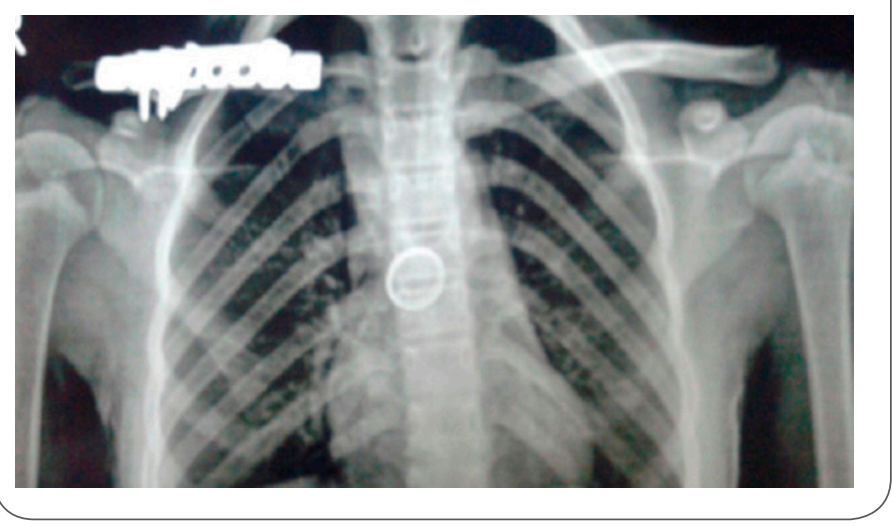

Figure 8: This photography shows appearance of the patient after plate removal.

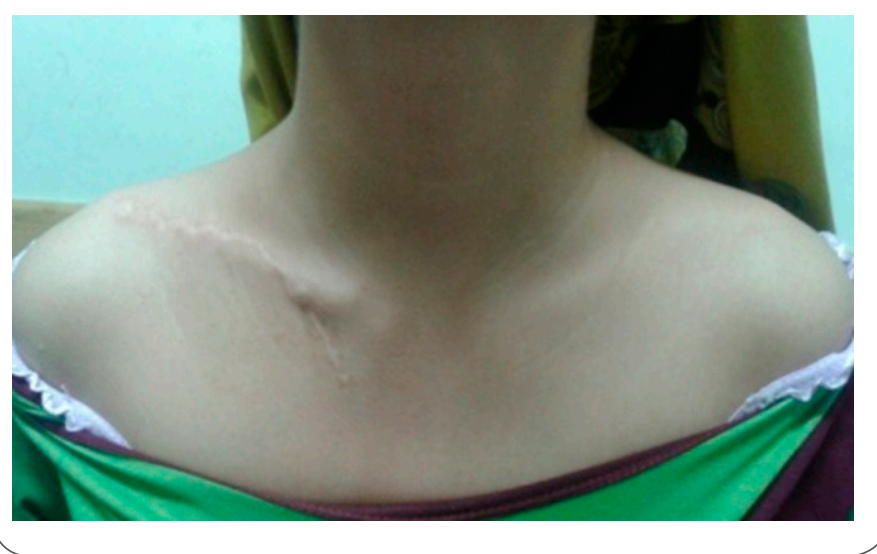




\section{Discussion}

Congenital pseudoarthrosis of clavicle (CPC) has been a rare entity in the practice that first reported by FitzWilliams in 1910 [6]. Although this anomaly usually exists at birth but often diagnosed late in childhood [2]. CPC mostly found in girls and in the mid-right clavicle [7]. Association with other structural abnormalities in cases with left-sided or bilateral involvement has been reported such as dextrocardia and cervical ribs, respectively [1] Possible genetic transmission of this disorder has been suggested with a postulated Autosomal dominant trait, as illustrated by Gibson and Carrel who described nine cases in a single family [3]. Currently most authors believe that the condition is caused by extrinsic pressure exerted on the budding clavicle by the adjacent pulsatile subclavian artery [1] Characteristically, radiological features of CPC include involvement of the middle part of the clavicle with a definitive separation into two parts. Both ends show bony hypertrophy with well defined cortical borders. The sternal half typically lies abnormal and anterior to acromial half [8]. The histological analysis of the resected pseudoarthrosis shows enchondral ossification on both sides of pseudoarthrosis and confirm that the CPC is due to failure of coalescence of the two primary ossification center of the clavicle [9].

Treatment is controversial. Surgical indication for many authors is the presence of symptoms, functional impairment or cosmetic deformities [5]. While some authors discourage surgical treatment for CPC because of the risk of nonunion, clavicle shortening and surgical scar [6]. Others recommended early surgical treatment for CPC [10].

The best time for surgery is controversial. Manuscripts reported surgery time is from 18 months till adulthood $[2,3,11,12,13]$. The best method of surgery is also controversial. The common feature of all surgical method is pseudoarthrosis resection. External fixator without bone graft has been described with good result, smaller scar and avoid second operation for hardware removal [7, 13, 14, 15]. Fixation with K-wire and plates with good results have been reported. In small children K-wire is a good option [5] but in older children plate has better outcome with lower complications [3]. Most authors prefer iliac crest bone graft to achieve union and maintain clavicle length $[2,5$, $13,16,17]$ but local bone graft $[9,16]$ or no bone graft $[7,18]$ are another options. In overall, we believed that because of osteoporotic nature of bone in this anomaly bone graft usage can be useful in treatment.

In summary, we described a patient with CPC of the right clavicle which is a rare entity. Because of difficulty with fixation in an osteoporotic bone, we recommended locking plate at the operating room. Because of the morbidity of iliac crest autologus bone graft, we suggest local bone resected be used as bone graft. At final follow up the operated clavicle was only $5 \mathrm{~mm}$ shorter than normal one and no clinical impairment was obvious. We recommend surgical treatment of CPC in the older children with pseudoarthrosis resected local bone grafting and locking plate for good results and better functional outcome and patient pleasure expected. 


\section{References}

1. Tony H T Sung, Eric M W Man, Augustine T S Chan, W K Lee. Congenital pseudarthrosis of the clavicle: a rare and challenging diagnosis.Hong Kong Med J. 2013; 19 (3): 265-7.

2. Galanopoulos I, Ashwood N, Garlapati AK, Fogg Q. Congenital pseudarthrosis of clavicle: illustrated operative technique and histological findings. BMJ Case Rep. 2012 Sep 21;

3. Chandran $P$, George $H$, James $L$ A.Congenital clavicular pseudarthrosis: comparison of two treatment methods. J Child Orthop. 2011; 5(1): 1-4.

4. Currarino G, Herring JA. Congenital pseudarthrosis of the clavicle. Pediatr Radiol. 2009; 39 (12): 1343-9.

5. Kołodziej L, Bohatyrewicz A, Kotrych D. Congenital pseudoarthrosis of the clavicle: is operative treatment necessary? A report of four cases and literature review. Chir Narzadow Ruchu Ortop Pol. 2008; 73 (4): 277-80, 252-6.

7. Persiani p, Molayem I, Villani C, Cadilhac C, Glorion C. Surgical treatment of congenital pseudarthrosis of the clavicle: A report on 17 case. Acta Orthop Belg. 2008; 74 (2): 161-6. Beslikas TA, Dadoukis,DJ Gigis IP, Nenopoulos SP, Christoforides JE.Congenital pseudarthrosis of the clavicle: a case report. Journal of Orthopaedic Surgery 2007; 15 (1): 87-90

8. Gomez-Brouchet A, Sales de Gauzy J, Accadbled F, Abid A, Delisle MB, Cahuzac JP.Congenital pseudarthrosis of the clavicle: a histopathological study in five patients. J Pediatr Orthop B. 2004; 13 (6): 399-401.

9. Ullot Font R, Cepero C S, Gargantilla VA, Hernández B S. Congenital pseudarthrosis of the clavicle: a review of nine cases. An Pediatr (Barc). 2006; 64 (3): 273-6. [Article in Spanish]

10. Glotzbecker MP, Shin EK, Chen NC, Labow BI, Waters PM. Salvage reconstruction of congenital pseudarthrosis of the clavicle with vascularized fibular graft after failed operative treatment: a case report. J Pediatr Orthop. 2009; 29 (4): 411-5.

11. Ettl V, Wild A, Krauspe R, Raab P.Surgical treatment of congenital pseudarthrosis of the clavicle: a report of three cases and review of the literature. Eur J Pediatr Surg. 2005; 15(1): 56-60.

12. Köster $G$, Kunze $E$, von Knoch $M$. Surgical treatment of congenital clavicular pseudarthrosis. Z Orthop Ihre Grenzgeb. 1999; 137 (5): 414-8. [Article in German]

13. JSchnall SB1, King JD, Marrero G. Congenital pseudarthrosis of the clavicle: a review of the literature and surgical results of six cases. Pediatr Orthop. 1988; 8 (3): 316-21.

14. Grogan DP, Love SM, Guidera KJ, Ogden JA. Operative treatment of congenital pseudarthrosis of the clavicle. J Pediatr Orthop. 1991; 11 (2): 176-80.
15. O'Leary E, Elsayed S, Mukherjee A, Tayton K. Familial pseudarthrosis of the clavicle: does it need treatment? Acta Orthop Belg. 2008; 74 (4): 437-40.

16. Magu NK, Singla R, Devgan A, Gogna P. Congenital pseudoarthrosis of the clavicle with bifurcation. Indian J Orthop 2014; 48 (4): 435-7

17. Gibson DA, Carroll N. Congenital pseudarthrosis of the clavicle. J Bone Joint Surg Br 1970; 52 (4): 629-43.

18. Ogata S, Uhthoff HK. The early development and ossification of the human clavicle-an embryologic study. Acta Orthop Scand. 1990; 61 (4): 330-4

\section{Comment on this article:}
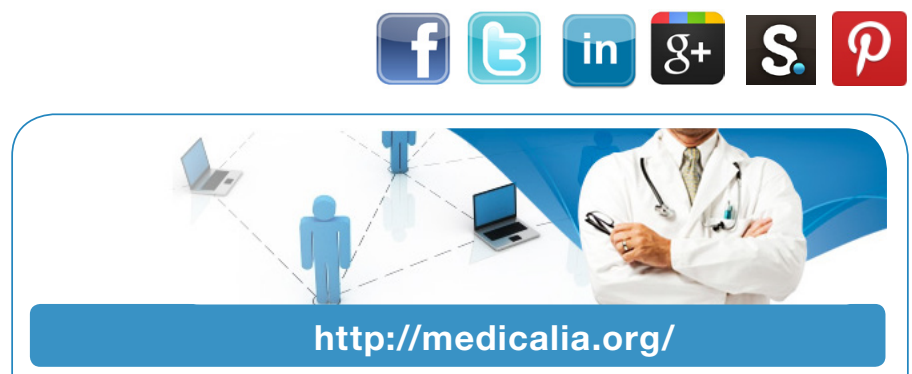

Where Doctors exchange clinical experiences, review their cases and share clinical knowledge. You can also access lots of medical publications for free. Join Now!

\section{Publish with iMedPub}

http://www.imed.pub

International Archives of Medicine is an open access journal publishing articles encompassing all aspects of medical science and clinical practice. IAM is considered a megajournal with independent sections on all areas of medicine. IAM is a really international journal with authors and board members from all around the world. The journal is widely indexed and classified Q1 in category Medicine. 